\title{
Concordance of KRAS/BRAF Mutation Status in Metastatic Colorectal Cancer before and after Anti-EGFR Therapy
}

\author{
S. Gattenlöhner, ${ }^{1}$ B. Etschmann, ${ }^{1}$ V. Kunzmann, ${ }^{2}$ A. Thalheimer, ${ }^{3}$ M. Hack, ${ }^{4}$ G. Kleber, ${ }^{5}$ \\ H. Einsele, ${ }^{2}$ C. Germer, ${ }^{2}$ and H.-K. Müller-Hermelink ${ }^{1}$ \\ ${ }^{1}$ Institute of Pathology, University of Würzburg, 97080 Würzburg, Germany \\ ${ }^{2}$ Department of Internal Medicine II, University of Würzburg, 97080 Würzburg, Germany \\ ${ }^{3}$ Department of Surgery, University of Würzburg, 97080 Würzburg, Germany \\ ${ }^{4}$ Institute of Pathology, Ostalb-Klinikum Aalen, 73430 Aalen, Germany \\ ${ }^{5}$ Department of Internal Medicine, Ostalb-Klinikum Aalen, 73430 Aalen, Germany
}

Correspondence should be addressed to S. Gattenlöhner, stefan.gattenloehner@mail.uni-wuerzburg.de

Received 30 August 2009; Revised 9 November 2009; Accepted 31 December 2009

Recommended by Francis Seow-Choen

Anti-EGFR targeted therapy is a potent strategy in the treatment of metastatic colorectal cancer (mCRC) but activating mutations in the KRAS gene are associated with poor response to this treatment. Therefore, KRAS mutation analysis is employed in the selection of patients for EGFR-targeted therapy and various studies have shown a high concordance between the mutation status in primary CRC and corresponding metastases. However, although development of therapy related resistance occurs also in the context of novel drugs such as tyrosine kinase-inhibitors the effect of the anti-EGFR treatment on the KRAS/BRAF mutation status itself in recurrent mCRC has not yet been clarified. Therefore, we analyzed $21 \mathrm{mCRCs}$ before/after anti-EGFR therapy and found a pre-/posttherapeutic concordance of the KRAS/BRAF mutation status in 20 of the 21 cases examined. In the one discordant case, further analyses revealed that a tumor mosaicism or multiple primary tumors were present, indicating that anti-EGFR therapy has no influence on KRAS/BRAF mutation status in mCRC. Moreover, as the preselection of patients with a KRAS ${ }^{w t}$ genotype for anti-EGFR therapy has become a standard procedure, sample sets such ours might be the basis for future studies addressing the identification of potential anti-EGFR therapy induced genetic alterations apart from KRAS/BRAF mutations.

Copyright (C) 2009 S. Gattenlöhner et al. This is an open access article distributed under the Creative Commons Attribution License, which permits unrestricted use, distribution, and reproduction in any medium, provided the original work is properly cited.

\section{Introduction}

Colorectal carcinoma (CRC) is one of the most common forms of malignant neoplasia and frequently takes a fatal course following metastasis [1]. CRC is a multipathway disease involving dysregulatory phenomena in a number of signal transduction pathways [2]. The epidermal growth factor receptor (EGFR), a tyrosine kinase receptor belonging to the ErbB family, is overexpressed in $25 \%-80 \%$ of CRCs and has been found to play a major role in the pathogenesis of CRC by inducing downstream signaling pathways such as the phosphatidylinositol-3-kinase/Akt and Ras/Raf/mitogen-activated protein kinase (MAPK) pathways, which are crucial in the regulation of cell growth, proliferation, apoptosis, invasion, migration, and angiogenesis [3]. Consequently, antibodies targeting EGFR, such as cetuximab and panitumumab, have been examined for therapeutic efficacy in CRC patients [4]. Although it was determined that combination therapy of irinotecan and cetuximab is significantly more successful in the treatment of metastatic CRC (mCRC) than irinotecan alone, the overall therapeutic response rate to combined cetuximab therapy is less than $30 \%$, suggesting that there are escape mechanisms present in many cases of CRC $[5,6]$. Among others, mutation of the genes encoding the Kirsten rat sarcoma viral oncogene homologue (KRAS) and the V-raf murine sarcoma viral oncogene homolog B1 (BRAF) wes established as two of these mechanisms and preselection of CRC patients with a $K R A S^{w t}$ genotype have been shown to increase the therapeutic efficacy of anti-EGFR therapy $[7,8]$. Therefore, clinical trials involving anti-EGFR therapy are now commonly conducted with patients preselected for $K R A S^{w t}$ mutation status 
TABle 1: Primer data for sequencing and allele specific PCR for KRAS exon 2 and BRAF exon 15 mutation analysis.

\begin{tabular}{ll}
\hline \multicolumn{1}{c}{ KRAS } \\
\hline$d 1$ & $5^{\prime}$-GAG TTT GTA TTA AAA GGT ACT \\
& GG-3' \\
$d 2$ & $5^{\prime}$-TAC TGG TGG AGT ATT TGA TAG \\
& TG-3' \\
$r 1+r 2$ & $5^{\prime}$-CTG TAT CAA AGA ATG GTC CTG-3' \\
\hline & \multicolumn{1}{c}{ BRAF } \\
\hline$d$ & $5^{\prime}$-TGC TTG CTC TGA TAG GAA AAT-3' \\
\hline
\end{tabular}

$[9,10]$. To ensure that therapy targeting EGFR is effective in primary CRC as well as in corresponding metastases, various studies have examined the concordance or discordance of KRAS and BRAF mutation status in primary CRC and corresponding metastases. Although the results of these studies appear contradictory in part, the majority of authors report high rates of concordance between the mutation status of KRAS in primary tumors and corresponding metastases $[4,9,11-16]$. In a study published recently by our group, KRAS mutation status was monitored in the primary tumors and corresponding metastases of 106 cases of mCRC [17]. Here, we found concordance in the mutation status of KRAS in 105 of 106 cases (Figure 1) and were able to show that the only case of discordance was due to a tumor mosaic or the coexistence of multiple primary tumors (Figure 2), a fact that could help in explaining the partially contradicting results reported in the past $[13,17]$. Moreover, in analogy to other types of cancer [18-20], therapy-related resistance based on a treatment-induced shift in KRAS and/or BRAF mutation status could also play a role in explaining the low therapeutic efficacy of anti-EGFR therapy in $\mathrm{mCRC}$ by rendering tumor cells initially responsive to anti-EGFR mAbs resistant to this therapeutic regimen [9].

\section{Materials and Methods}

49 individual specimens of 21 metastatic CRCs and corresponding metastases collected before and after combined therapy with cetuximab were examined using CGH, certified PCR/DNA sequencing protocols (KRAS exon 2, Gl12/13; $B R A F$ exon 15, V600E) as well as allele-specific PCR [8].

The majority of samples analyzed in this approach derived from the sample pool of 106 mCRC with 270 syn/metachronic metastases used in our earlier study on the concordance of KRAS mutation status in primary CRC and corresponding metastases [17]. Biopsy sets were collected before and after combined cetuximab therapy, whereby the samples collected before therapy were taken from primary CRCs and/or liver metastases, while those gathered after therapy were from metastases in different locations, predominantly the liver (Table 2). Each CRC studied was clinically documented as a single primary malignant tumor in the colon/rectum and all metastases were identified as such by a characteristic "CRC-like" immunohistochemical profile

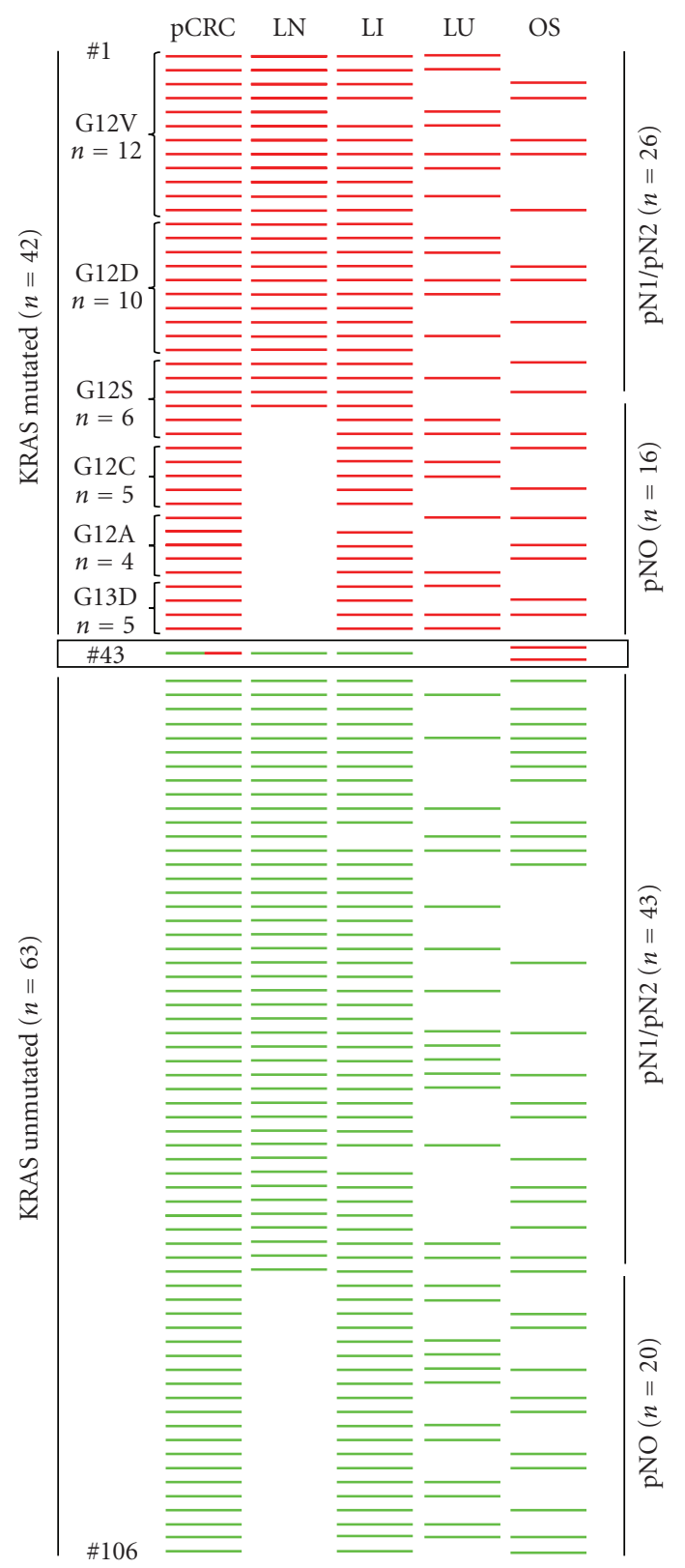

FIGURE 1: Overview of patient data from an investigation of the concordance of 106 primary CRCs and 270 corresponding metastases syn-/metachronic metastases. Each line represents an individual patient with primary CRC and metastatic manifestations. Red bars demonstrate KRAS mutation positive CRCs $(n=42)$ with corresponding lymph node metastases $(n=26)$, liver metastases $(n$ $=40)$, lung metastases $(n=22)$, and other sites $(n=18)$ including bone marrow $(n=6)$, soft tissue $(n=5)$, and peritoneum $(n=$ $7)$. Green bars show KRAS mutation negative CRCs $(n=63)$ with corresponding lymph node metastases $(n=43)$, liver metastases $(n=61)$, lung metastases $(n=28)$, and other sites (OS) $(n=$ 32 ) including bone marrow $(n=10)$, soft tissue $(n=13)$ and peritoneum $(n=9)$. In case \#43 a heterogeneously differentiated primary CRC (see also Figure 2) showed a KRAS mosaicism (red and green bars in pCRC) with detection of KRAS mutation G12V in other sites (OS, undifferentiated soft tissue und peritoneal metastases (red bars)) but not in moderately differentiated lymph node and liver metastases (LN and LI, green bars). LN: lymph node; LI: liver; LU: lung; OS: other sites. 
(cytokeratin 20 positive, cytokeratin 7 negative). Following pathohistological characterization, tumor cells were enriched to $>90 \%$ from $4-610 \mu \mathrm{m}$ slices using microdissection. Two independent samples from each specimen were incubated overnight in lysis buffer containing proteinase $\mathrm{K}$ at $56^{\circ} \mathrm{C}$ and DNA was subsequently extracted by column affinity chromatography (Qiagen DNA Minikit, Cat No 51306).

CGH was performed as previously described [17]. Briefly, DNA was labeled by nick translation with biotin16-dUTP (Roche Diagnostics, Mannheim, Germany). After inactivation of DNase I (Roche Diagnostics, Mannheim, Germany) equal amounts $(1 \mu \mathrm{g})$ of tumor and reference DNA (DIG-labeled DNA from placental tissue of a healthy newborn) were cohybridized on metaphase slides (Vysis, Downers Grove, IL). Signals were visualized with a Zeiss Axiophot fluorescence microscope and analyzed with the ISIS digital image analysis system (MetaSystems, Altlussheim, Germany).

$K R A S$ and $B R A F$ mutation analyses were performed on two independent samples from all primary tumors/ metastases using protocols described previously [8]. Briefly, DNA was amplified using Taq DNA Polymerase (Invitrogen Cat. No. 10342-020) and allele specific primers (Eurofins, see Table 1). Amplificates were visualized in $2 \%$ agarose gels and purified from the gels using column affinity chromatography (QIAquick Gel Extraction Kit, Qiagen Cat. No. 28704). Sequencing PCR was performed using PCR primers (see Table 1) and ABI BigDye Terminator v3.1 Cycle Sequencing RR-100 (ABI Heidelberg, Germany) as described [17].

\section{Results}

In the first part of our study we analyzed 106 metastatic CRCs with at least 2 multifocal and syn-/metachronic metastases $(n=270)$ using PCR/DNA sequencing protocols certified by the German Society for Pathology (exon 2, Glycin 12 and Glycin13) as well as allele-specific PCR approaches. As shown in Figure 1, we observed concordance of the KRAS mutation status between primary CRCs and all corresponding metastases in 105 of 106 patients. However in one case (Figure 1 \#43) of a KRAS mutation G12V positive moderately differentiated and undifferentiated primary CRC (Figure 2(a)), the mutation was detectable in soft tissue and peritoneal metastases with infiltrates from the undifferentiated tumour fraction (Figures 2(b) and 2(c)), but not in moderately differentiated lymph node and liver metastases (Figures $2(\mathrm{e})$ and 2(f)). Microdissected subfractions of the primary heterogeneous CRC showed a corresponding mutational mosaicism with detection of KRAS mutation G12V only in the undifferentiated tumour areas (Figures $2(\mathrm{~d})$ and $2(\mathrm{~g})$ ).

In the second part of the study we addressed the question, whether combined cetuximab therapy might influence the KRAS/BRAF mutation status in mCRC. Therefore 16 patients from the described sample pool (Figure 1) as well as 5 novel patients (including case \#4, see Table 2) suffering from mCRC were analyzed for the KRAS/BRAF mutation status using the above mentioned molecular and immunohistochemical techniques.

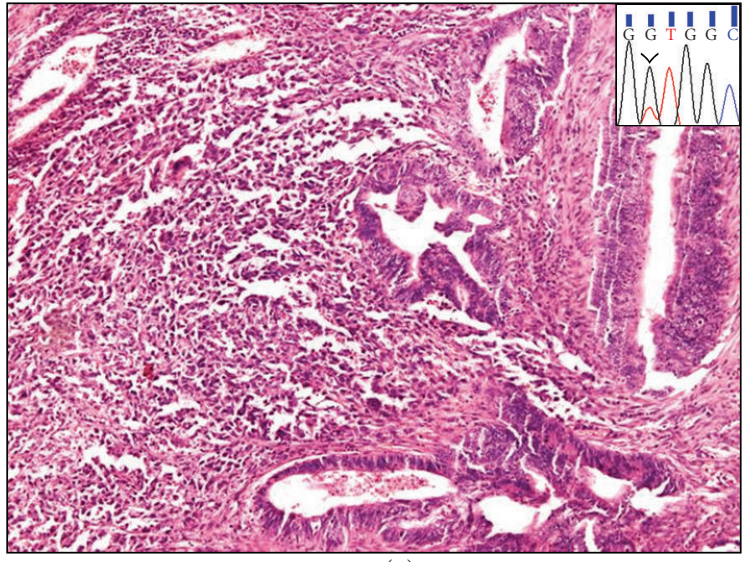

(a)

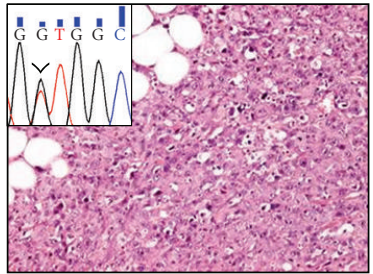

(b)

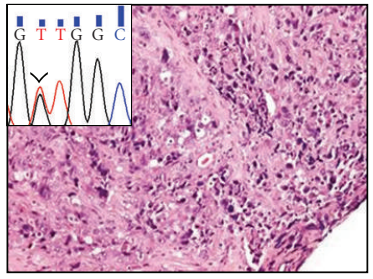

(c)

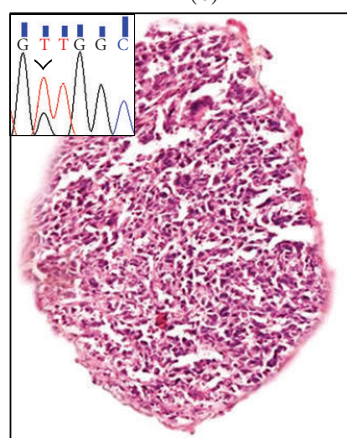

(d)

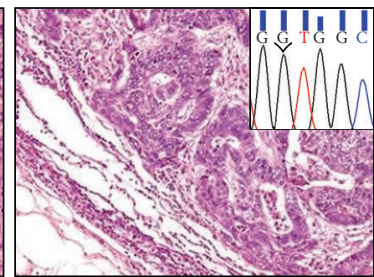

(e)

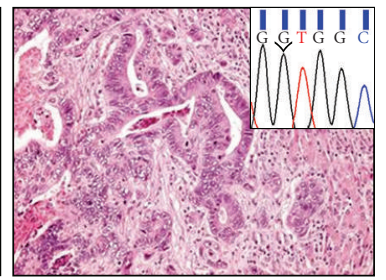

(f)

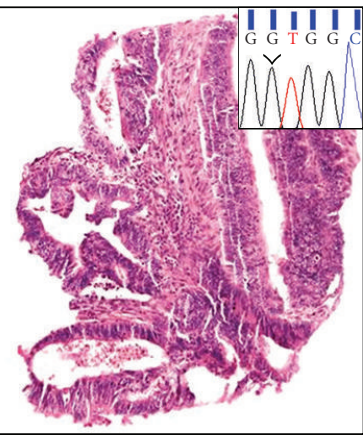

(g)
FIGURE 2: Morphological changes and results of KRAS mutation analyses in case \#43 of a heterogeneously differentiated CRC with mosaicism for KRAS mutation G12D. In Figure 2(a) moderately (right half) and undifferentiated (left half) tumor areas reveal positive detection of KRAS mutation G12V (inset). In contrast, only in soft tissue (b) and peritoneal (c) metastases harbouring exclusively undifferentiated tumor infiltrates an identical KRAS mutation was detectable ((b) and (c) insets), whereas in lymph node (e) and liver (f) metastases with moderately differentiated tumor infiltrates only, no KRAS mutation was found ((e) and (f) insets). After microdissection of undifferentiated (d) and moderately differentiated $(\mathrm{g})$ areas from primary CRC the KRAS mutation $\mathrm{G} 12 \mathrm{~V}$ was only detectable in the undifferentiated fraction ((d), inset). Images were produced with a $\mathrm{B} \times 50$ microscope (Olympus, Hamburg, Germany) and a DP50 digital camera with DP-Soft 5.0 software (Olympus, Hamburg, Germany). 
TABLe 2: Overview of the clinical patient data. 20 of 21 patients show concordance of the KRAS (exon 2, Gly 12/13) and BRAF (exon 15, V600E) mutation status between samples of primary CRCs and/or corresponding metastases before and after combined cetuximab therapy. In one case (\#4), the primary CRC had a mutated KRAS gene (Gly12Asp), while the liver metastasis biopsied after combined cetuximab therapy showed a $K R A S^{w t}$ genotype. BRAF mutation status in this case was concordant between the samples gathered before and after anti-EGFR therapy.

\begin{tabular}{|c|c|c|c|c|c|}
\hline Case no. & Sex/Age & $\begin{array}{l}\text { Date and localisation of } \\
\text { tumor manifestaion }\end{array}$ & $\begin{array}{c}\text { KRAS } \\
\text { Gly12/13 } \\
\text { (exon2) }\end{array}$ & $\begin{array}{l}\text { BRAF V600E } \\
\quad(\text { exon15) }\end{array}$ & Anti-EGFR therapy \\
\hline \multirow[t]{2}{*}{1} & \multirow[t]{2}{*}{$\mathrm{M} / 51 \mathrm{y}$} & 09/05 primary CRC & Gly12Val & WT & $\begin{array}{l}\text { 01/07-04/07 } \\
\text { Folfiri/Cetuximab (PD) }\end{array}$ \\
\hline & & $\begin{array}{l}11 / 07 \text { small bowel } \\
\text { metastasis }\end{array}$ & Gly12Val & WT & dead $05 / 08$ \\
\hline \multirow[t]{2}{*}{2} & \multirow[t]{2}{*}{$\mathrm{M} / 71 \mathrm{y}$} & $11 / 02$ soft tissue & Gly12Cys & WT & $\begin{array}{l}\text { 09/04-08/05 } \\
\text { Folfiri/Cetuximab (PR) }\end{array}$ \\
\hline & & $\begin{array}{l}03 / 06 \text { mesocolon } \\
\text { transversum metastasis }\end{array}$ & Gly12Cys & WT & \\
\hline \multirow[t]{2}{*}{3} & \multirow[t]{2}{*}{$\mathrm{M} / 46 \mathrm{y}$} & 03/07 primary CRC & WT & WT & $\begin{array}{l}\text { 08/07-06/08 } \\
\text { Folfiri/Cetuximab (PR) }\end{array}$ \\
\hline & & 02/09 peritoneal carcinosis & WT & WT & \\
\hline \multirow[t]{2}{*}{4} & \multirow[t]{2}{*}{$\mathrm{M} / 68 \mathrm{y}$} & $11 / 06$ primary CRC & Gly12Asp & WT & $\begin{array}{l}\text { 04/07-02/08 } \\
\text { Fufox/Cetuximab(PR) }\end{array}$ \\
\hline & & 03/08 liver metastasis & WT & WT & \\
\hline \multirow[t]{2}{*}{5} & \multirow[t]{2}{*}{$\mathrm{F} / 56 \mathrm{y}$} & 07/08 primary CRC & Gly12Asp & WT & $\begin{array}{l}\text { 07/08-09/08 } \\
\text { Fufox/Cetuximab (PD) }\end{array}$ \\
\hline & & $12 / 08$ peritoneal carcinosis & Gly12Asp & WT & dead $12 / 08$ \\
\hline \multirow[t]{2}{*}{6} & \multirow[t]{2}{*}{$\mathrm{M} / 71 \mathrm{y}$} & 12/05 primary CRC & Gly12Val & WT & $\begin{array}{l}\text { 01/06-07/06 } \\
\text { Folfiri/Cetuximab (PD) }\end{array}$ \\
\hline & & $12 / 06$ liver metastasis & Gly12Val & WT & dead 04/08 \\
\hline \multirow[t]{2}{*}{7} & \multirow[t]{2}{*}{$\mathrm{F} / 58 \mathrm{y}$} & 01/08 primary CRC & WT & WT & $\begin{array}{l}\text { 04/08-07/08 } \\
\text { Folfiri/Cetuximab (PD) }\end{array}$ \\
\hline & & 07/08 peritoneal carcinosis & WT & WT & dead $07 / 08$ \\
\hline \multirow[t]{2}{*}{8} & \multirow[t]{2}{*}{$\mathrm{F} / 44 \mathrm{y}$} & 11/07 primary CRC & WT & WT & $\begin{array}{l}\text { 05/08-03/09 } \\
\text { Folfox/Cetuximab (PR) }\end{array}$ \\
\hline & & $12 / 08$ peritoneal carcinosis & WT & WT & \\
\hline \multirow{3}{*}{9} & \multirow{3}{*}{$\mathrm{F} / 66 \mathrm{y}$} & 02/04 primary CRC & Gly12Ser & WT & $\begin{array}{l}\text { 07/06-09/06 } \\
\text { Folfox/Cetuximab (PR) }\end{array}$ \\
\hline & & $\begin{array}{l}11 / 05+04 / 06 \text { liver } \\
\text { metastasis }\end{array}$ & Gly12Ser & WT & $\begin{array}{l}\text { 07/06-09/06 } \\
\text { Folfox/Cetuximab (PD) }\end{array}$ \\
\hline & & 11/06 lung metastasis & Gly12Ser & WT & $\begin{array}{l}\text { 09/06-11/06 } \\
\text { Folfiri/Avastin (PD) }\end{array}$ \\
\hline \multirow[t]{2}{*}{10} & \multirow[t]{2}{*}{$\mathrm{M} / 77 \mathrm{y}$} & $11 / 05$ primary CRC & Gly13Asp & WT & $\begin{array}{l}\text { 12/05-09/06 Folfox }+ \\
\text { Cetuximab (PD) }\end{array}$ \\
\hline & & 07/06 lymph node & Gly13Asp & WT & $\begin{array}{l}\text { 10/06-02/07 Folfiri }+ \\
\text { Avastin (PD) dead 05/07 }\end{array}$ \\
\hline \multirow{3}{*}{11} & \multirow{3}{*}{$\mathrm{M} / 63 \mathrm{y}$} & 05/07primary CRC & WT & WT & $\begin{array}{l}\text { 05/07-07/08 } \\
\text { Folfiri/Cetuximab (PR) }\end{array}$ \\
\hline & & $01 / 08$ liver metastasis & WT & WT & 10/08-05/09 Folfox (PR) \\
\hline & & 06/09 liver metastasis & WT & WT & \\
\hline \multirow[t]{2}{*}{12} & \multirow[t]{2}{*}{$\mathrm{M} / 67 \mathrm{y}$} & 07/07 liver metastasis & WT & WT & $\begin{array}{l}\text { 08/07-04/08 } \\
\text { Folfox/Cetuximab (PR) }\end{array}$ \\
\hline & & 01/08 liver metastasis & WT & WT & \\
\hline \multirow{3}{*}{13} & \multirow{3}{*}{$\mathrm{M} / 59 \mathrm{y}$} & 09/07 primary CRC & WT & WT & \\
\hline & & $10 / 07$ liver metastasis & WT & WT & $\begin{array}{l}\text { 11/07-03/08 } \\
\text { Folfiri/Cetuximab (PR) }\end{array}$ \\
\hline & & 05/08 liver metastasis & WT & WT & \\
\hline
\end{tabular}


TABLE 2: Continued.

\begin{tabular}{|c|c|c|c|c|c|}
\hline Case no. & Sex/Age & $\begin{array}{l}\text { Date and localisation of } \\
\text { tumor manifestaion }\end{array}$ & $\begin{array}{c}\text { KRAS } \\
\text { Gly12/13 } \\
\text { (exon2) } \\
\end{array}$ & $\begin{array}{l}\text { BRAF V600E } \\
\quad(\text { exon15) }\end{array}$ & Anti-EGFR therapy \\
\hline \multirow{3}{*}{14} & \multirow{3}{*}{$\mathrm{M} / 61 \mathrm{y}$} & 07/02 primary CRC & WT & WT & $\begin{array}{l}\text { 10/07-07/08 } \\
\text { Folfox/Cetuximab (PR) }\end{array}$ \\
\hline & & 05/04 liver metastasis & WT & WT & \\
\hline & & 07/08 peritoneal carcinosis & WT & WT & Since 12/08 Folfox (PR) \\
\hline \multirow{3}{*}{15} & \multirow{3}{*}{$\mathrm{F} / 68 \mathrm{y}$} & 09/05 primary CRC & WT & V600E & 10/05-02/06 Folfox (PD) \\
\hline & & 05/06 soft tissue & WT & V600E & $\begin{array}{l}\text { 03/06-08/06 } \\
\text { Folfiri/Cetuximab (PR) }\end{array}$ \\
\hline & & 01/07 soft tissue & WT & V600E & $\begin{array}{l}01 / 07-05 / 07 \\
\text { Cetuximab/Irinotecon } \\
\text { (PD) } \\
\text { dead } 06 / 07\end{array}$ \\
\hline \multirow{5}{*}{16} & \multirow{5}{*}{$\mathrm{M} / 75 \mathrm{y}$} & 07/00 primary CRC & Gly12Asp & WT & \\
\hline & & 07/03 lung metastasis & Gly12Asp & WT & 08/03-07/04 Folfox (PD) \\
\hline & & 08/03 liver metastasis & & & 08/04-08/05 Folfiri (PD) \\
\hline & & 08/05 liver metastasis & Gly12Asp & WT & $\begin{array}{l}\text { 08/05-04/06 } \\
\text { Folfiri/Cetuximab (PD) } \\
04 / 06-02 / 07 \\
\text { Cetuximab+CPT- } \\
11(\mathrm{PD}) \\
\text { 02/07-04/07 } \\
\text { Panitumumab (PD) }\end{array}$ \\
\hline & & 04/07 ascites & Gly12Asp & WT & dead $05 / 07$ \\
\hline \multirow[t]{2}{*}{17} & \multirow[t]{2}{*}{$\mathrm{M} / 69 \mathrm{y}$} & 06/02 primary CRC & Gly13Asp & WT & $\begin{array}{l}\text { 06/02-09/02 Folfox (PR) } \\
06 / 03-12 / 03 \text { Folfox (PR) } \\
07 / 04-01 / 06 \text { Folfiri (PD) } \\
03 / 06-05 / 06 \text { Cetuximab } \\
+ \text { CPT-11 (PD) } \\
09 / 06-02 / 07 \text { Folfox (PD) }\end{array}$ \\
\hline & & 07/07 mesocolon metastasis & Gly13Asp & WT & dead 09/07 \\
\hline \multirow[t]{2}{*}{18} & \multirow[t]{2}{*}{$\mathrm{M} / 75 \mathrm{y}$} & 01/04 primary CRC & Gly12Asp & WT & $\begin{array}{l}\text { 06/07-10/07 } \\
\text { Capecitabine/Cetximab } \\
\text { (PD) }\end{array}$ \\
\hline & & 01/08 peritoneal carcinosis & Gly12Asp & WT & dead $03 / 08$ \\
\hline \multirow[t]{2}{*}{19} & \multirow[t]{2}{*}{$\mathrm{F} / 61 \mathrm{y}$} & 07/08 primary CRC & WT & WT & $\begin{array}{l}\text { 07/08-03/09 } \\
\text { Folfiri/Cetuximab (PR) }\end{array}$ \\
\hline & & 05/09 liver metastasis & WT & WT & \\
\hline \multirow[t]{2}{*}{20} & \multirow[t]{2}{*}{$\mathrm{M} / 56 \mathrm{y}$} & 05/08 primary CRC & WT & WT & $\begin{array}{l}\text { 06/08-12/08 } \\
\text { Folfox/Cetuximab (PR) }\end{array}$ \\
\hline & & 06/09 lung metastasis & WT & WT & \\
\hline \multirow[t]{2}{*}{21} & \multirow[t]{2}{*}{$\mathrm{M} / 72 \mathrm{y}$} & 09/08 primary CRC & WT & WT & $\begin{array}{l}\text { 10/08-02/09 } \\
\text { Folfiri/Cetuximab (PR) }\end{array}$ \\
\hline & & 01/09 liver metastasis & WT & WT & \\
\hline
\end{tabular}

Response evaluation (according to RECIST criteria): PD: progressive disease; SD: stable disease; PR: partial remission; CR: complete remission.

We hereby observed a concordance in the KRAS and $B R A F$ mutation status between samples from primary CRCs and/or corresponding metastases before and after combined cetuximab therapy in 20 of 21 patients (Table 2). The timespan between first and last sampling ranged between 4 and 81 months (average 25,8 months) and the patients involved in the study received 1 to 5 rounds of therapy (average 1,8 rounds) during this period. 


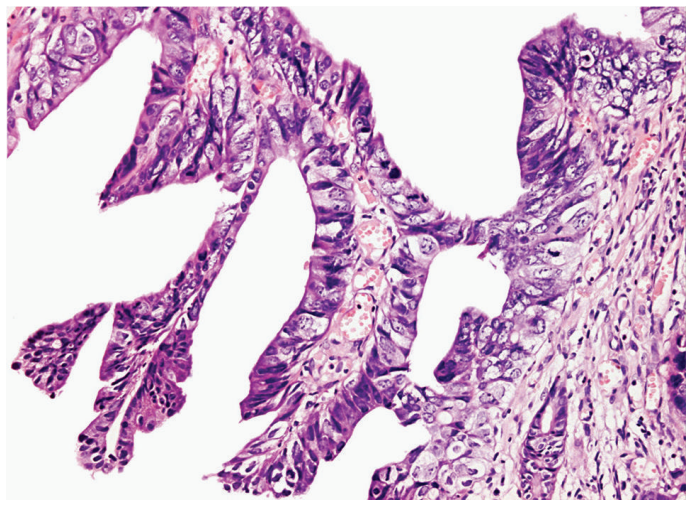

(a)
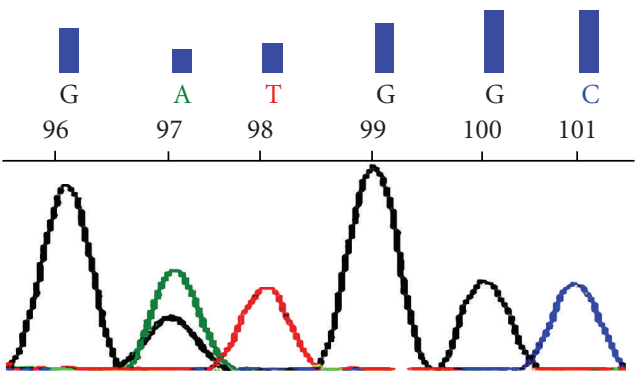

(c)
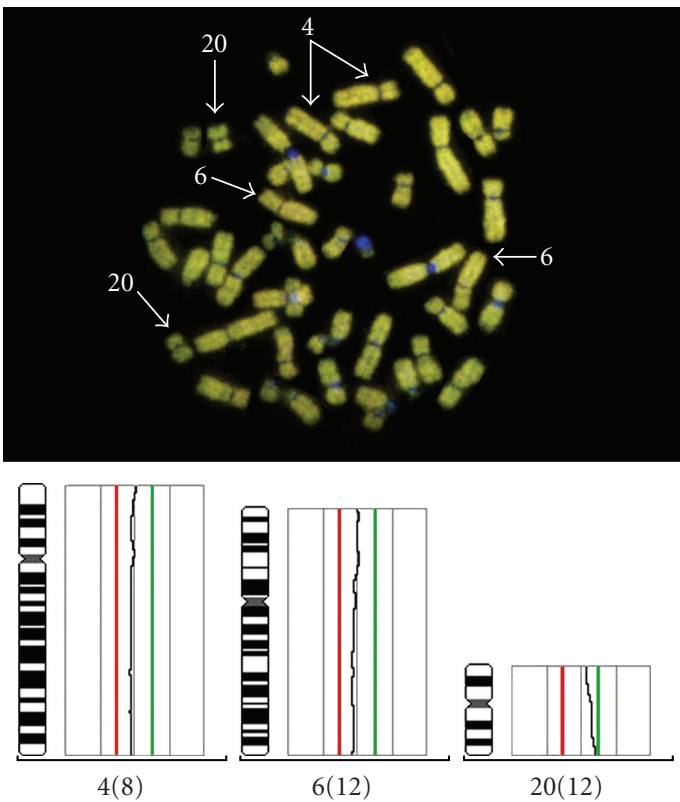

(e)

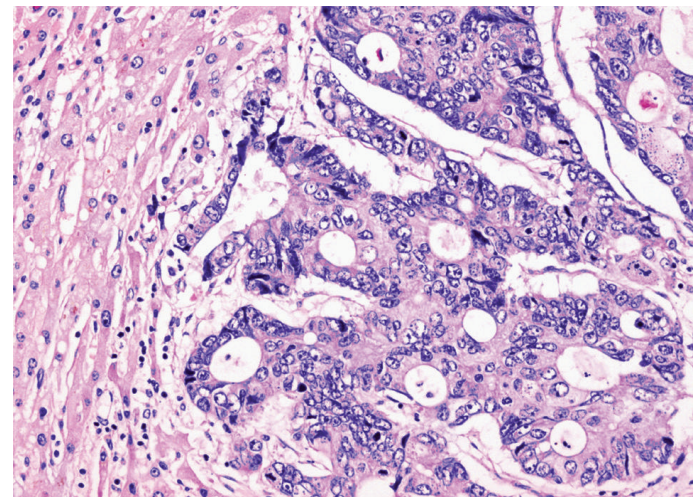

(b)

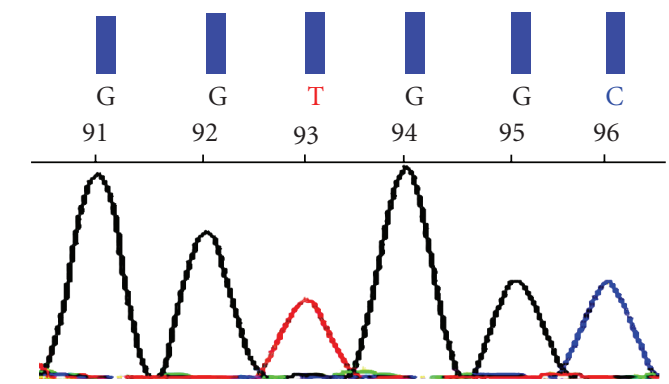

(d)
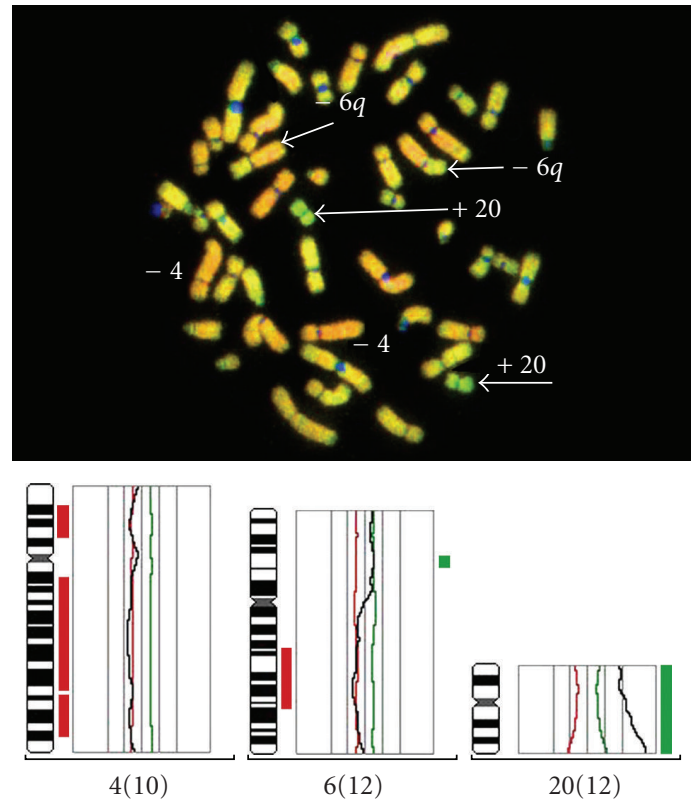

(f)

FIGURE 3: Further analysis of biopsies from the patient with a discordant KRAS mutation status before and after anti-EGFR therapy (\#4, see Table 2) showing varying morphology between primary CRC with papillary tissue organization (a) and liver metastasis with tubular tissue organization (b). KRAS mutations analysis of corresponding specimens demonstrate detection of KRAS mutation exon 2 Gly12D (c) in primary CRC whereas an unmutated KRAS status in the liver metastasis was detectable (d). In fluorescence scan and data analysis of CGH only in the liver metastasis biopsied after treatment (f) but not in the primary CRC (e) a decrease in fluorescence of chromosomes 4 and 6 and an increase of chromosome 20 (arrows) could be seen. 
In the one case of discordance between KRAS mutation status before and after combined cetuximab therapy (case \#4), a mutated KRAS gene (Exon $2 \mathrm{G12D}$ ) was found in the primary CRC, while no KRAS mutation was observed in a liver metastasis sample obtained after combined cetuximab therapy (Table 2). Further analysis of the biopsy samples in this patient revealed that the primary CRC sampled before therapy and the liver metastasis biopsied after therapy showed differences not only in their KRAS mutation status but also in morphology and overall genetic composition (Figure 3). While the primary tumor was predominantly organized in a papillary fashion (Figure 3(a)), the liver metastasis displayed a distinctly tubular organization (Figure 3(b)). As mentioned above, microdissected samples gathered from each of these specimens showed distinct genetic sequences in exon 2 of the KRAS gene. While a mutated KRAS gene (Exon 2 G12D) was observed in the primary CRC (Figure 3(c)), a $K R A S^{w t}$ genotype was found in the liver metastasis (Figure 3(d)). Moreover, comparative genomic hybridization performed on the samples revealed that each of these displayed different genetic alterations. In comparison to the primary CRC (Figure 3(e)), samples from the liver metastasis showed sequence losses in chromosomes 4 and 6, while gains were observed in chromosome 20 (Figure 3(f)).

\section{Discussion}

Development of therapy-related resistance is a frequent phenomenon in cancer and also occurs in the context of novel drugs such as monoclonal antibodies and tyrosine kinase inhibitors. In gastrointestinal stromal tumors (GISTs), the most common mesenchymal neoplasm of the gastrointestinal tract, mechanisms of resistance to imatinib mesylate $\left(\right.$ Gleevec $^{\mathrm{R}}$ ) include both de novo and, more frequently, acquired resistance, which may occur after several months of drug administration and most often is based upon an acquired second mutation in the c-kit and PDGFR $\alpha$ genes $[18,19]$. In B-cell lymphoma, resistance to the chimeric anti-CD20 monoclonal antibody rituximab, the first monoclonal antibody to have been registered for the treatment of B-cell lymphomas, is suggested to be due to reduced expression of $\mathrm{CD} 20$, the failure of rituximab to trigger the cells leading to inhibition of antibody-dependent and complement-dependent cell toxicity (ADCC and CDC), as well as hyperactivation of antiapoptotic signaling pathways such as p38 MAP kinase, NF-kappaB, ERK1, and AKT [20].

In the first part of our study we analyzed a welldocumented cohort of 106 metastatic CRCs with 270 syn/metachronic metastases concerning the KRAS mutation status showing an overall concordance of the KRAS mutation status in primary CRCs and metastases in $99 \%$ of the cases examined that stands in good accordance to previous reports [21]. However, apart from potentially coexisting secondary malignancies, the KRAS mutation mosaicism found in one heterogeneously differentiated CRC (\#43, Figures 1 and 2) may explain the discordant results concerning this trait in primary CRCs and metastases reported previously [12, $13,22]$ and underlines the necessity for diligent clinical and histological characterization of any atypical tumour manifestation in mCRC to prevent misleading results with negative impact on anti-EGFR targeted therapies.

The second and major part of our study was to investigate whether therapy-related resistance due to acquired second KRAS/BRAF mutations also occurs in metastatic colorectal cancer after anti-EGFR therapy. Therefore we analyzed 49 individual specimens from $21 \mathrm{mCRC}$ collected before and after combined cetuximab therapy. Of the 21 patients examined in this study, 20 showed concordance between the KRAS mutation status before and after combined cetuximab therapy, while the rate of concordance for BRAF was $100 \%$. In one patient (case \#4, Table 2) that did not derive from the above mentioned sample pool of $106 \mathrm{mCRC}$, the KRAS mutation status was discordant between the samples collected before and after cetuximab therapy, but due to further analysis of these samples with clearly different morphological and genomic features (Figure 3 ) it might be suggested that populations of carcinoma cells heterogeneous with respect to wild-type and mutant KRAS were probably present in the primary carcinoma, but the metastatic clone derived from a KRAS negative population, as reported previously $[22,23]$.

The results of this study provide first evidence that secondary KRAS/BRAF mutations do not play a major role in therapy-related resistance to anti-EGFR antibody treatment in mCRC, although it cannot be excluded that KRAS/BRAF mutations beyond Glycin12/13 KRAS exon2 and V600E BRAF exon15 as well as secondary resistance due to combinational chemotherapies (as in most patients investigated) are responsible for therapy-related resistance in mCRC. Moreover, as the preselection of patients with a $K R A S^{w t}$ genotype for cetuximab therapy has become a standard procedure, sample sets such as the one used in this study will have to be conserved carefully for use in future studies particularly with respect to analyses addressing the identification of anti-EGFR therapy-induced genetic alterations apart from KRAS/BRAF mutations.

\section{Acknowledgments}

The authors thank Mrs. Margrit Bonengel, Mrs. Jaqueline Maar, Mrs. Sophie Brüggemeier, and Mr. Erwin Schmitt for expert technical assistance. This study was supported by the Wilhelm-Sander-Stiftung (Grant 2007.068.01) and the Deutsche Forschungs-Gesellschaft (DFG-SFB-Transregio 52, TPA8).

\section{References}

[1] A. Jemal, R. Siegel, E. Ward, T. Murray, J. Xu, and M. J. Thun, "Cancer statistics, 2007," CA: A Cancer Journal for Clinicians, vol. 57 , no. 1 , pp. 43-66, 2007.

[2] J. R. Jass, "Colorectal cancer: a multipathway disease," Critical Reviews in Oncogenesis, vol. 12, no. 3-4, pp. 273-287, 2006.

[3] F. Ciardiello and G. Tortora, "Drug therapy: EGFR antagonists in cancer treatment," The New England Journal of Medicine, vol. 358, no. 11, pp. 1160-1174, 2008.

[4] N. A. Reynolds and A. J. Wagstaff, "In the treatment of metastatic colorectal cancer," Drugs, vol. 64, no. 1, pp. 109118, 2004. 
[5] D. Cunningham, Y. Humblet, S. Siena, et al., "Cetuximab monotherapy and cetuximab plus irinotecan in irinotecanrefractory metastatic colorectal cancer," The New England Journal of Medicine, vol. 351, no. 4, pp. 337-345, 2004.

[6] C. S. Karapetis, S. Khambata-Ford, D. J. Jonker, et al., "K-ras mutations and benefit from cetuximab in advanced colorectal cancer," The New England Journal of Medicine, vol. 359, no. 17, pp. 1757-1765, 2008.

[7] V. Boige, D. Malka, J. Taieb, J.-P. Pignon, and M. Ducreux, "Colorectal cancer: prognostic molecular markers," Gastroenterologie Clinique et Biologique, vol. 28, no. 1, pp. 21-32, 2004.

[8] J. H. van Krieken, A. Jung, T. Kirchner, et al., "KRAS mutation testing for predicting response to anti-EGFR therapy for colorectal carcinoma: proposal for an European quality assurance program," Virchows Archiv, vol. 453, no. 5, pp. 417431, 2008.

[9] S. Benvenuti, A. Sartore-Bianchi, F. Di Nicolantonio, et al., "Oncogenic activation of the RAS/RAF signaling pathway impairs the response of metastatic colorectal cancers to antiepidermal growth factor receptor antibody therapies," Cancer Research, vol. 67, no. 6, pp. 2643-2648, 2007.

[10] C. J. Allegra, J. M. Jessup, M. R. Somerfield, et al., "American society of clinical oncology provisional clinical opinion: testing for KRAS gene mutations in patients with metastatic colorectal carcinoma to predict response to anti-epidermal growth factor receptor monoclonal antibody therapy," Journal of Clinical Oncology, vol. 27, no. 12, pp. 2091-2096, 2009.

[11] F. Loupakis, L. Pollina, I. Stasi, et al., "PTEN expression and KRAS mutations on primary tumors and metastases in the prediction of benefit from cetuximab plus irinotecan for patients with metastatic colorectal cancer," Journal of Clinical Oncology, vol. 27, no. 16, pp. 2622-2629, 2009.

[12] S. Artale, A. Sartore-Bianchi, S. M. Veronese, et al., "Mutations of KRAS and BRAF in primary and matched metastatic sites of colorectal cancer," Journal of Clinical Oncology, vol. 26, no. 25, pp. 4217-4219, 2008.

[13] S. Tortola, R. Steinert, M. Hantschick, et al., "Discordance between $\mathrm{K}$-ras mutations in bone marrow micrometastases and the primary tumor in colorectal cancer," Journal of Clinical Oncology, vol. 19, no. 11, pp. 2837-2843, 2001.

[14] B. Suchy, C. Zietz, and H. M. Rabes, "K-ras point mutations in human colorectal carcinomas: relation to aneuploidy and metastasis," International Journal of Cancer, vol. 52, no. 1, pp. 30-33, 1992.

[15] F. Al-Mulla, J. J. Going, E. T. Sowden, A. Winter, I. R. Pickford, and G. D. Birnie, "Heterogeneity of mutant versus wild-type Ki-ras in primary and metastatic colorectal carcinomas, and association of codon-12 valine with early mortality," Journal of Pathology, vol. 185, no. 2, pp. 130-138, 1998.

[16] J. J. Oudejans, R. J. C. Slebos, F. A. N. Zoetmulder, W. J. Mooi, and S. Rodenhuis, "Differential activation of ras genes by point mutation in human colon cancer with metastases to either lung or liver," International Journal of Cancer, vol. 49, no. 6, pp. 875-879, 1991.

[17] S. Gattenlohner, C. Germer, and H. K. Muller-Hermelink, "Kras mutations and cetuximab in colorectal cancer," The New England journal of medicine, vol. 360, no. 8, pp. 835-836, 2009.

[18] C. R. Antonescu, "Targeted therapies in gastrointestinal stromal tumors," Seminars in Diagnostic Pathology, vol. 25, no. 4, pp. 295-303, 2008.

[19] G. Apice, A. Milano, G. S. Bruni, R. V. Iaffaioli, and F. Caponigro, "Medical treatment of gastrointestinal stromal tumors: state of the art and future perspectives," Reviews on Recent Clinical Trials, vol. 1, no. 1, pp. 35-42, 2006.

[20] B. Bonavida, "Rituximab-induced inhibition of antiapoptotic cell survival pathways: implications in chemo/ immunoresistance, rituximab unresponsiveness, prognostic and novel therapeutic interventions," Oncogene, vol. 26, no. 25, pp. 3629-3636, 2007.

[21] D. Santini, F. Loupakis, B. Vincenzi, et al., "High concordance of KRAS status between primary colorectal tumors and related metastatic sites: implications for clinical practice," Oncologist, vol. 13, no. 12, pp. 1270-1275, 2008.

[22] C. Oliveira, S. Velho, C. Moutinho, et al., "KRAS and BRAF oncogenic mutations in MSS colorectal carcinoma progression," Oncogene, vol. 26, no. 1, pp. 158-163, 2007.

[23] F. Al-Mulla, J. J. Going, E. T. Sowden, A. Winter, I. R. Pickford, and G. D. Birnie, "Heterogeneity of mutant versus wild-type Ki-ras in primary and metastatic colorectal carcinomas, and association of codon-12 valine with early mortality," Journal of Pathology, vol. 185, no. 2, pp. 130-138, 1998. 


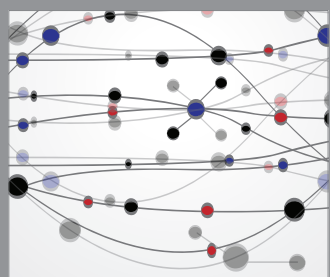

The Scientific World Journal
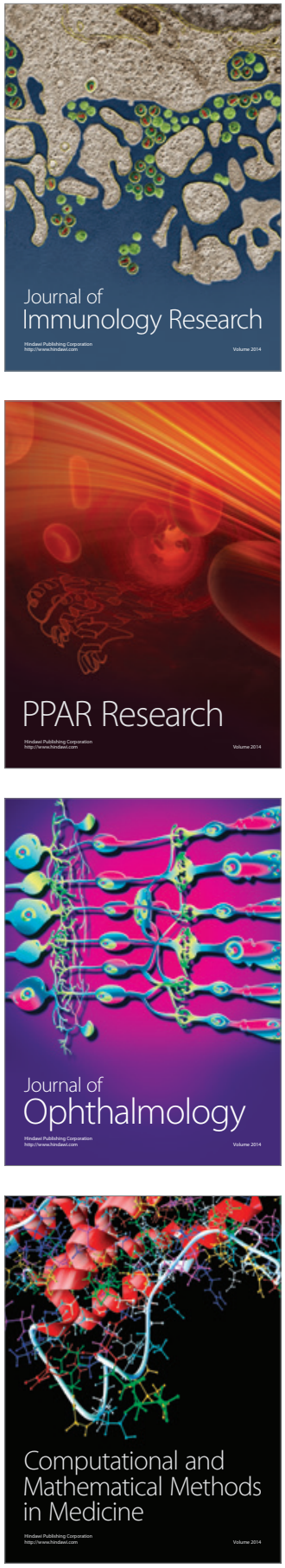

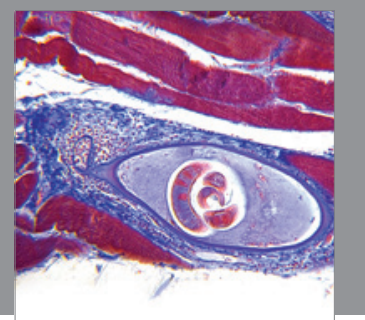

Gastroenterology

Research and Practice
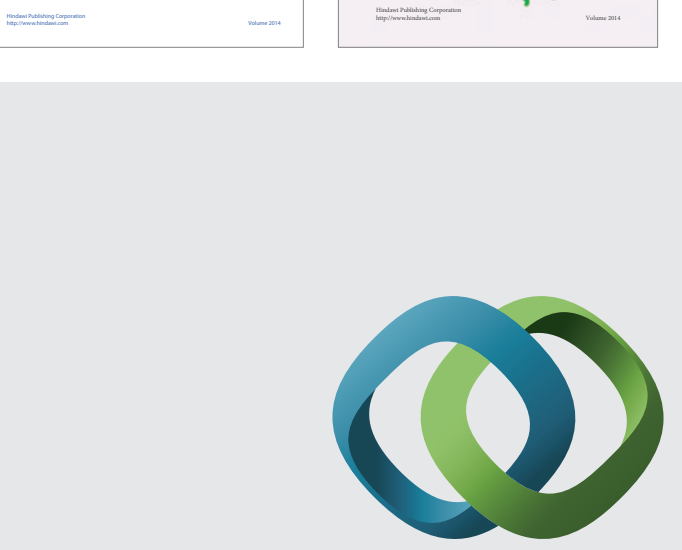

\section{Hindawi}

Submit your manuscripts at

http://www.hindawi.com
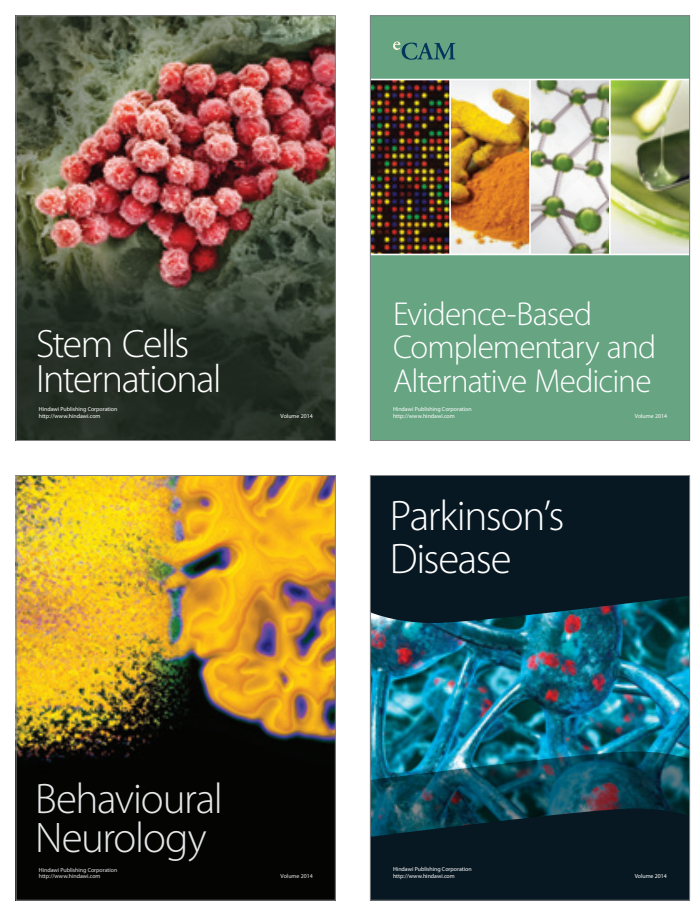

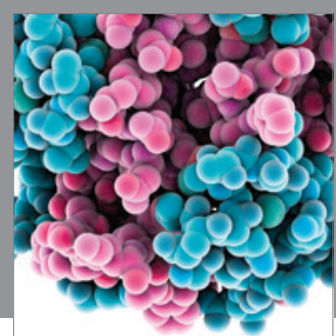

Journal of
Diabetes Research

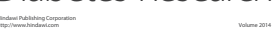

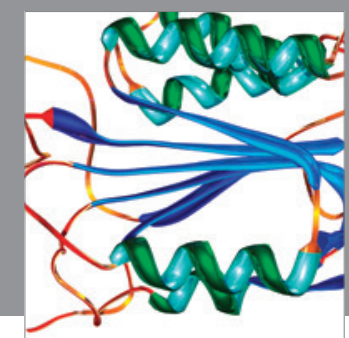

Disease Markers
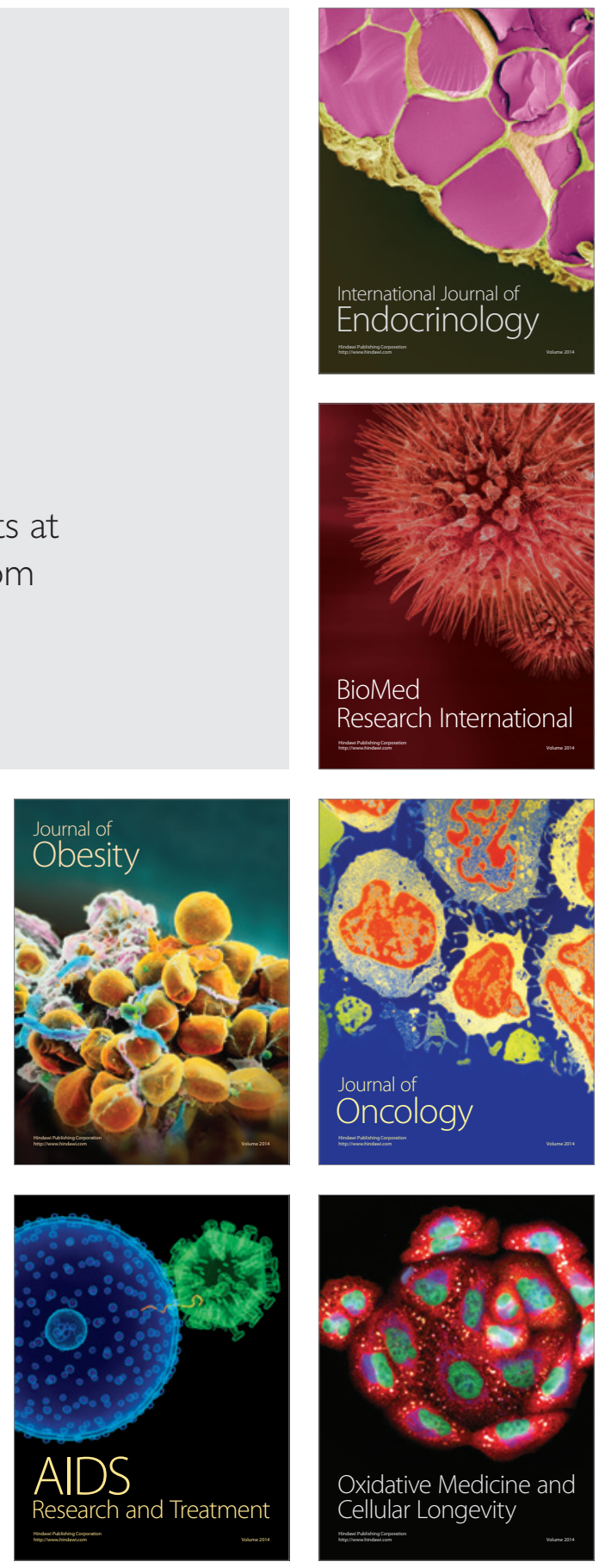